\title{
Nonspatial and Subdivision-Specific Working Memory Deficits after Selective Lesions of the Avian Prefrontal Cortex
}

\author{
Bettina Diekamp, ${ }^{1}$ Anna Gagliardo, ${ }^{2}$ and Onur Güntürkün1 \\ ${ }^{1}$ Biopsychology, Department of Psychology, Ruhr-University Bochum, 44780 Bochum, Germany, and 2 Department of \\ Ethology, Ecology, and Evolution, University of Pisa, I-56126 Pisa, Italy
}

Association areas in the avian forebrain are shown to subserve higher cognitive functions, including working memory. One of these areas, the neostriatum caudolaterale (NCL) of pigeons, has been functionally compared with the mammalian prefrontal cortex (PFC) because of its prominent role in spatial delay and reversal tasks and its innervation by the dopaminergic system that modulates these functions. However, whereas the PFC maintains in working memory information of different domains, the essential role of the NCL in working memory has been demonstrated only for spatial tasks. To investigate whether the avian NCL is also crucial for nonspatial working memory functions, pigeons were tested in an object-related (color) delayed matching-to-sample (DMTS) task. Bilateral lesions were placed in the entire, dorsal, or ventral NCL to test for possible functional subdivisions that were proposed to exist on the basis of neurochemical and behavioral data. Pigeons with total, dorsal, and ventral NCL lesions showed significant deficits in their DMTS performance, whereas controls were not impaired. Thus, the avian NCL is critically involved in nonspatial working memory processes. Recovery from performance deficits was observed in animals with ventral or total NCL lesions, whereas animals with dorsal NCL lesions showed no improvement. Ventral NCL may mediate perseverative behavior, whereas dorsal NCL might be involved in active working memory. Differences in the connections of these subdivisions with striatal areas and other association areas in the frontomedial forebrain underline functional differences. The data indicate a possible segregation of functions in the avian NCL.

Key words: delayed matching to sample; working memory; prefrontal cortex; perseveration; birds; association area
Numerous investigations have instigated the debate about whether areas of the avian forebrain are functionally equivalent to mammalian association areas (Mogensen and Divac, 1982; Rehkämper and Zilles, 1991; Braun et al., 1999). One of these regions, the neostriatum caudolaterale (NCL) of birds, subserves higher cognitive functions, including working memory, reversal learning, and response inhibition (Mogensen and Divac, 1982, 1993; Gagliardo et al., 1996, 1997; Güntürkün, 1997a; Hartmann and Güntürkün, 1998; Aldavert-Vera et al., 1999; Diekamp et al., 2000). Because of these functions, its dense dopaminergic innervation (Divac et al., 1985; Durstewitz et al., 1998), its anatomic connections (Leutgeb et al., 1996; Metzger et al., 1998; Kröner and Güntürkün, 1999), and the response properties of its neurons (Diekamp et al., 2002; Kröner et al., 2002), the NCL has been functionally compared with the mammalian prefrontal cortex (PFC) (Divac and Mogensen, 1985; Mogensen and Divac, 1993).

A core function of the mammalian PFC is the ability to maintain information on-line for subsequent actions. Indeed, NCL units are activated during delay periods in which the animal has to maintain previously perceived information (Diekamp et al., 2002). Furthermore, NCL lesions cause severe spatial delay deficits (Mogensen and Divac, 1982, 1993; Gagliardo et al., 1997; Güntürkün, 1997a). Because all sensory modalities are repre-

\footnotetext{
Received April 30, 2002; revised July 29, 2002; accepted Aug. 9, 2002.

This research was supported by the Deutsche Forschungsgemeinschaft (SPP 1001 and Gu 227/5-2), the Deutscher Akademischer Austauschdienst (Vigoni Program), and a Consiglio Nazionale delle Ricerche travel grant to A.G. We are especially indebted to Ivan Divac, a great mentor and friend, who initiated this study.

Correspondence should be addressed to Bettina Diekamp, Biopsychologie, GAFO 05/618, Fakultät für Psychologie, Ruhr-Universität Bochum, 44780 Bochum, Germany. E-mail: bettina.diekamp@ruhr-uni-bochum.de.

Copyright (C) 2002 Society for Neuroscience 0270-6474/02/229573-08 $\$ 15.00 / 0$
}

sented within the NCL (Kröner and Güntürkün, 1999) and because NCL neurons code primarily for relevant events rather than specific sensory stimuli during a behavioral task (Kalt et al., 1999), it is possible that the NCL integrates information across sensory domains. However, all lesion studies of the NCL and working memory thus far have involved spatial information. Therefore, our primary goal was to investigate whether the avian NCL is involved in nonspatial object-related working memory. To this end, we used a delayed matching-to-sample (DMTS) task in which the stimulus color needed to be maintained in memory during its absence. DMTS is used frequently to assess prefrontal functions in different animals, including humans (Rushworth et al., 1997; Postle et al., 2000).

The second aim of the study was to investigate the role of possible subdivisions within the NCL, because numerous PFC studies have discussed the role of subregions in the processing of different stimulus domains (Levy and Goldman-Rakic, 2000). For the NCL of pigeons, subdivisions were proposed on the basis of behavioral (Riters and Bingman, 1999), connectional (Leutgeb et al., 1996; Metzger et al., 1998; Kröner and Güntürkün, 1999), and neurochemical (Riters et al., 1999) data. The neurochemical subdivision into a dorsal and a ventral component also coincides with hodological data showing that only the dorsal NCL receives afferents from multimodal thalamic nuclei (Korzeniewska and Güntürkün, 1990; Güntürkün and Kröner, 1999) and other association areas of the forebrain implicated in imprinting, learning, and memory formation (Bradley et al., 1985; Metzger et al., 1998; Kröner and Güntürkün, 1999; Foster and Bottjer, 2001). Partial NCL lesions were placed to allow a comprehensive study of the contribution of functional subfields to working memory outside the spatial domain. 


\section{MATERIALS AND METHODS}

Subjects. Twenty-two experimentally naive, unsexed pigeons (Columba livia) of local stock at the age of 1-5 years were used in the experiments. They were housed in an open aviary. One week before training, they were deprived of food and maintained at $80-85 \%$ of their free-feeding weights throughout the experiment. They always had ad libitum access to grit and water. All subjects were trained and tested $5 \mathrm{~d} /$ week. Animal procedures were conducted in accordance with the NIH Guide for the Care and Use of Laboratory Animals and according to standards of the American Psychological Association.

Apparatus and stimuli. Four identically configured operant chambers $(34 \times 33 \times 36 \mathrm{~cm}$, depth by width by height), each controlled by a computer via digital input-output boards (CIO-PDISO8; Computer Boards, Inc.), were used in the training and DMTS tasks. Each chamber was equipped with three opaque operant keys $(2 \mathrm{~cm}$ in diameter) located on the back panel $22 \mathrm{~cm}$ above the floor and spaced $10 \mathrm{~cm}$ apart. Three light bulbs were mounted behind each pecking key to transilluminate the keys homogeneously with white, red, or green light. The colors were not matched for brightness. White light was used during the operant conditioning and pretraining sessions, and red and green lights were used during training and DMTS sessions. The feeder combined with a feeder light was located in the center of the back panel $5 \mathrm{~cm}$ above the floor. A home light was fixed centrally on the ceiling.

Pretraining. All pigeons were trained initially to peck reliably on the center key whenever it was illuminated with white light. After a single peck, the light was extinguished, and the pigeons were reinforced with 3 $\mathrm{sec}$ access to food that was followed by a $5 \mathrm{sec}$ intertrial interval. In the subsequent training step, each trial began with the illumination of the center key. A single peck to one of the lateral keys during this phase terminated the trial and started a $15 \mathrm{sec}$ intertrial interval that was followed by a repetition trial, whereas a peck on the illuminated center key extinguished the center light and was followed immediately by the illumination of either the right or left choice key with white light. Food reinforcement was contingent on activation of the illuminated lateral key, whereas activation of the dark choice key resulted in a $10 \mathrm{sec}$ time-out period during which all lights were turned off. Training sessions consisted of 80 trials separated by $15 \mathrm{sec}$ intertrial intervals. The number of pecks on the center key necessary to proceed was increased gradually from 1 to 15. The criterion for the pretraining phase was a performance of at least $90 \%$ correct responses within a session.

Training with colored operant keys. During this training phase, operant keys were illuminated with either red or green instead of white light. Activation of the stimulus light, either red or green, behind the central key indicated the start of a trial. The center light stayed on until the pigeon had pecked the center key 15 times. Immediately thereafter $(0 \mathrm{sec}$ delay), either the right-side or left-side key was illuminated randomly, but always in the same color as the just extinguished center stimulus. Pigeons were reinforced as usual with $3 \mathrm{sec}$ access to food after pecking the correct, i.e., illuminated, key and were punished with a $10 \mathrm{sec}$ time-out after pecking the incorrect, i.e., dark key. Training continued until pigeons finished 80 trials within 15 min and reached a performance level of at least $90 \%$ correct responses.

DMTS task. The parameters and test conditions were adapted from earlier investigations involving delay tasks in pigeons (Urcuioli et al., 1999). Trials began with the presentation of the sample stimulus, i.e., the illumination of the central key with either red or green light. Pecking one of the lateral keys during this phase terminated the trial, started the intertrial interval, and was followed by a repetition trial. Otherwise, the sample stimulus remained on until 15 pecks were made to the center key. This marked the beginning of the delay period, during which the sample stimulus was no longer visible. At the end of the delay period, the two lateral choice keys were shown, one illuminated with red and the other with green light. Matching of the choice stimulus with the sample stimulus shown previously was considered a correct response, and pecking the correct key once was rewarded immediately with $3 \mathrm{sec}$ access to food. Pecking on the key with the color that did not match the previous sample stimulus was punished with a $10 \mathrm{sec}$ time-out period. No correction trials were introduced. The next trial started after a $15 \mathrm{sec}$ intertrial interval. Each session consisted of 80 trials.

Four different stimulus combinations were possible, on the basis of the randomization of the color of the central sample and the subsequent position of the matching green or red choice stimulus. Each combination was presented randomly 20 times in a session consisting of 80 trials. Birds were first trained on a $0 \mathrm{sec}$ delay task until they reached a performance level of $80 \%$ correct matches in two successive sessions. Subsequently, they were introduced to progressively longer delays but always had to reach the criterion before longer delays were used. All of the pigeons were trained to their individual best performance levels $(2.0,4.0$, or 8.0 $\mathrm{sec})$. On the basis of the maximum delay that they mastered, different delay schedules were selected for each individual that always included a zero delay, the maximum delay, and three delays spaced between these values. Over the last six sessions before surgery (preoperative tests), all pigeons were required to reach an overall criterion of $80 \%$ correct responses.

Postoperative DMTS tests. After surgery and a 3-5 d rest, animals were tested using the same DMTS paradigm and retention intervals as before surgery. Within $10 \mathrm{~d}$, six sessions were conducted to assess short-term lesion effects (postoperative I test period). All animals were subsequently given a recovery period of 21-29 d with no test sessions at all before they were tested in six additional sessions to investigate the long-term effects of lesions (postoperative II test period).

Grain-grit discrimination task. In the grain-grit discrimination task, pigeons had to distinguish between white-grayish kardi grains (Sorghum bicolor) and small pebbles of similar size and shape. This is a standard task commonly used to test the sensorimotor performance of birds. The same procedures were used as described by Güntürkün and Kesch (1987). Briefly, pigeons were allowed to peck and search for 30 grains in $30 \mathrm{gm}$ grit for $30 \mathrm{sec}$. During each session, all pecks and the number of grains found were counted. Each pigeon was tested 10 times over a 2 week period before surgery and again 10 times during the first week of postoperative testing, starting 3-5 d after surgery.

Surgery. On the basis of their learning scores during the training of the delay task, pigeons were assigned to four matched lesion groups: total NCL $(n=6)$, dorsal NCL $(n=5)$, ventral NCL $(n=6)$, and controls $(n=$ 5). All animals were anesthetized with chloral hydrate $(20 \% ; 2 \mathrm{ml} / \mathrm{kg}$, i.m.) and placed in a stereotaxic device. Lesion electrodes $(0.25 \mathrm{~mm}$ tungsten wire) insulated with Isonel-31 (exposed tip, 0.2 or $0.8 \mathrm{~mm}$ ) were lowered stereotactically into relevant brain areas, and a current of $25 \mathrm{~mA}$ (radiofrequency generator; Radionics Inc.) was applied. All lesions were placed bilaterally according to stereotaxic coordinates (Karten and Hodos, 1967) and the outline of the NCL by Waldmann and Güntürkün (1993). Several lesions were necessary to cover the dorsal NCL: at anterior (A) 4.5: lateral (L) 4.0, L 5.0, L 6.0, and L 7.0; at A 5.0: L 4.5, L 5.5, and L 6.5; at A 5.5: L 4.0, L 5.0, and L 6.0; at A 6.0: L 4.5, L 5.5, and L 6.5; and at A 6.5: L 4.0, L 5.0, and L 6.0. For all dorsal lesions, the tip of the lesion electrode was $2 \mathrm{~mm}$ below the surface of the brain, and the current was applied for $5 \mathrm{sec}$. Lesions of the ventral NCL were placed at the following locations: at A 4.0, L 7.0; at A 4.5, L 7.5; at A 5.0, L 8.0; at A 5.5, L 8.5; and at A 6.0, L 8.5. Electrode tips were located $3 \mathrm{~mm}$ below the surface of the brain, and currents were applied for $8-10 \mathrm{sec}$. Both dorsal and ventral lesion sites were combined for total NCL lesions. In control animals, procedures were the same as for total NCL lesioned birds, but no current was applied to the stereotactically placed electrodes. At the end of the surgery, the skull was closed with dental acrylic, and the incision was sutured.

Histology and reconstruction of lesions. At completion of the behavioral experiments, animals were anesthetized lethally with equithesine $(0.55$ $\mathrm{ml} / 100$ gm body weight) and perfused intracardially with $0.9 \%$ saline followed by $4 \%$ buffered paraformaldehyde. The brains were removed, and coronal sections $(40 \mu \mathrm{m})$ were processed by standard histological procedures and stained with cresyl violet. Lesions were reconstructed at intervals of $250 \mu \mathrm{m}$ from A 3.00 to A 11.00 with an image analysis system (AnalySIS, Münster, Germany) and transferred onto standard sections derived from the pigeon brain atlas (Karten and Hodos, 1967). For each animal, the total lesion volumes (in cubic millimeters) for the left, right, and both hemispheres and the percentage damage of the left and right side relative to the volume of the entire NCL (L\%, R\%) were measured. The same measurements were also taken for the subdivisions of the NCL (dorsal, ventral). In addition, any damage to adjacent brain areas was reconstructed and measured.

Data analysis. As a measure of performance in the grain-grit discrimination test, the average discrimination accuracy in percentage was calculated as the number of grains consumed divided by the number of pecks $\times 100$. Motor activity of the pigeons was assessed by the total number of pecks during the $30 \mathrm{sec}$ period. Values were averaged over 10 preoperative tests and over 10 sessions during the first postoperative test period. Pecking activity and discrimination performance were analyzed statistically by separate repeated-measures ANOVAs involving the factors lesion groups and test periods (preoperative and postoperative).

In the DMTS task, several response measures were taken and used for 
additional analysis: (1) percentage correct matching choices for each delay and for each session; (2) response times, i.e., the time between the end of the retention interval and the choice response to one of the two side keys; (3) number of perseverative responses in the choice of color; and (4) number of perseverative responses to the spatial position of the response key. If the pigeon made the same choice as in the previous trial with respect to either color or spatial position, this was counted as one perseverative response. On the basis of the randomization of position and color of stimuli, a certain number of perseverative responses is necessary for a perfect performance. Thus, the color and spatial perseveration score was calculated for each session as the number of perseverative responses given by the animals divided by the number of color or spatial repetitions required for perfect performance (Granon et al., 1994). Scores below 1.0 indicate a tendency to alternate choices with respect to color or spatial position, whereas scores higher than 1.0 denote perseverative behavior.

Response measures were analyzed by a three-factorial ANOVA with groups (one control and three lesion groups) as between factors and with test periods (three periods: preoperative, postoperative I, and postoperative II) and delays (three levels: 0, 0.5-1.0, and 1.5-2.0 sec) as repeatedmeasures factors. Because only delays of up to $2.0 \mathrm{sec}$ were mastered by all animals, DMTS trials with longer delays were discarded from the statistical analysis. To account for individual differences in the preoperative performance, the postoperative performance of each animal was expressed in percentage relative to its preoperative levels, and difference scores were calculated between the preoperative (defined as 100\%) and postoperative relative performance levels. These difference scores were used in a separate three-factorial ANOVA with groups as between factors and with delays and the two postoperative test periods as repeated-measures factors. Perseveration behavior was analyzed with a two-way ANOVA with lesion treatment as main and test periods as repeated-measurement factors. The statistical significance was set at $p<$ 0.05 for all tests. If appropriate, planned comparisons (Bonferroni corrected) were used to test for differences between session blocks or between lesion and control groups.

\section{RESULTS}

\section{Histology}

Data of two animals, one of the total and one of the dorsal lesion group, were excluded from all analyses because the birds died a few days after surgery. Location and size of the lesions, i.e., total lesion volume and relative lesion size of the target brain areas, differed between lesion groups (Fig. 1). Bilateral total damage ranged from 25.0 to $139.5 \mathrm{~mm}^{3}$. Between 11.5 and $56.6 \%$ of the total NCL was lesioned. Lesions of animals assigned to the different lesion groups were found to have affected primarily the targeted area. In all animals of the dorsal and ventral lesion groups, at least $20 \%$ of the relevant subdivision was affected. In the total lesion group, 35.6$56.5 \%$ of the NCL was damaged, with each subdivision lesioned by at least $20 \%$. Minor collateral damage occurred in areas outside the borders of the NCL and included the overlying area corticoidea dorsolateralis, the surrounding neostriatum caudale, the anteriorly located hyperstriatum ventrale, and the archistriatum. In animals of the dorsal and ventral lesion groups, damage to areas outside the NCL amounted to $<9 \%$ of a volume equivalent to the total NCL volume, and in three subjects, no damage at all was found outside the borders of the NCL. In the total lesion group, collateral damage was also small, amounting to a volume of $<15 \%$ of the NCL, except for one animal, in which a volume equivalent to $37 \%$ of the NCL size was lost.

\section{Behavior}

\section{Grain-grit discrimination task}

One animal of the total lesion group showed very low activity and inconsistent behavior in the preoperative sessions of the graingrit discrimination task and therefore was excluded from the analysis. In general, lesioned and sham-operated animals tested 3-5 d after surgery pecked steadily. Because lesion groups were not matched for pecking activity, they differed with respect to overall pecking activity in this task $\left(F_{(3,15)}=3.605 ; p=0.038\right)$. However, no differences were observed in the average number of pecks performed in preoperative compared with postoperative sessions $\left(F_{(3,15)}=0.723 ; p=0.409\right)$. There was also no interaction between the effects of lesion treatment and test period on the pecking activity $\left(F_{(3,15)}=1.165 ; p=0.356\right)$. Discrimination performance in the grain-grit task was also not affected by lesion treatment $\left(F_{(3,15)}=0.468 ; p=0.709\right)$. In addition, performance did not depend on the testing period $\left(F_{(1,15)}=1.747 ; p=0.206\right)$, and no significant interaction was found between these factors $\left(F_{(3,15)}=2.750 ; p=0.079\right)$. Thus, lesions had no effect on motor activity or discrimination accuracy.

\section{DMTS task}

Preoperative performance. In the DMTS task, no difference in overall performance between the controls and any of the lesion groups during the six preoperative sessions was observed (Fig. $2 A, B)$. On average, all groups performed at a level of at least $88 \%$ correct responses, with better performance at a $0 \mathrm{sec}$ delay than at the $2 \mathrm{sec}$ delay. A two-way ANOVA with treatment groups (four groups) and delays (three different levels) as repeatedmeasures factors revealed no differences in preoperative performance between the groups $\left(F_{(3,16)}=1.639 ; p=0.219\right)$, a highly significant effect of the delay on the performance $\left(F_{(2,32)}=\right.$ $24.239 ; p<0.001)$, and no interaction effect $\left(F_{(6,32)}=1.333 ; p=\right.$ $0.272)$.

Postoperative performance. To test whether postoperative behavioral performance of the DMTS task was related directly to the total lesion size or damage in either the right or the left forebrain, correlation analyses were performed on lesion volumes and average percentage correct responses during the two postoperative testing periods. None of the correlations were found to be significant (all $r$ values $<0.361 ; p>0.118$ ). Thus, performance was not affected simply by the size or the side of the tissue damage that was inflicted.

The effects of lesion groups, test period (preoperative, postoperative I, and postoperative II), and delay length on the percentage correct choices in the DMTS were analyzed in a three-way ANOVA, with test period and delays as repeated-measurement factors. The factor test period had a significant effect on performance $\left(F_{(2,32)}=10.102 ; p<0.001\right)$. Performance was lower in the first postoperative compared with the preoperative test period and improved between the first and the second test periods (both $p$ values $<0.01$; Bonferroni post hoc tests). The factor delay length also had a highly significant effect on performance $\left(F_{(2,32)}=\right.$ 42.341; $p<0.001$ ) (Fig. $2 A$ ), which decreased with longer delay intervals. In addition, the lesion treatment had a significant effect on performance $\left(F_{(3,16)}=5.197 ; p=0.011\right)$. Post hoc tests revealed that the dorsal NCL lesion group made significantly fewer correct choices than controls and animals with total NCL lesions (both $p$ values $<0.05$ ) but not compared with animals of the ventral NCL lesion group. Interactions between test period and delay or both factors and lesion treatment were not significant. However, the ANOVA revealed a significant interaction between lesion treatment and test period $\left(F_{(6,32)}=4.174 ; p=0.003\right)$. Detailed post hoc analyses showed that all lesion groups had a significant decrease in performance between preoperative levels and the first postoperative test period (all $p$ values $<0.05$ ) (Fig. $2 B$ ). This was not the case for controls, which remained at their presurgery performance levels throughout both postsurgical test periods. Additional analyses showed that the ventral and total NCL lesion groups improved 

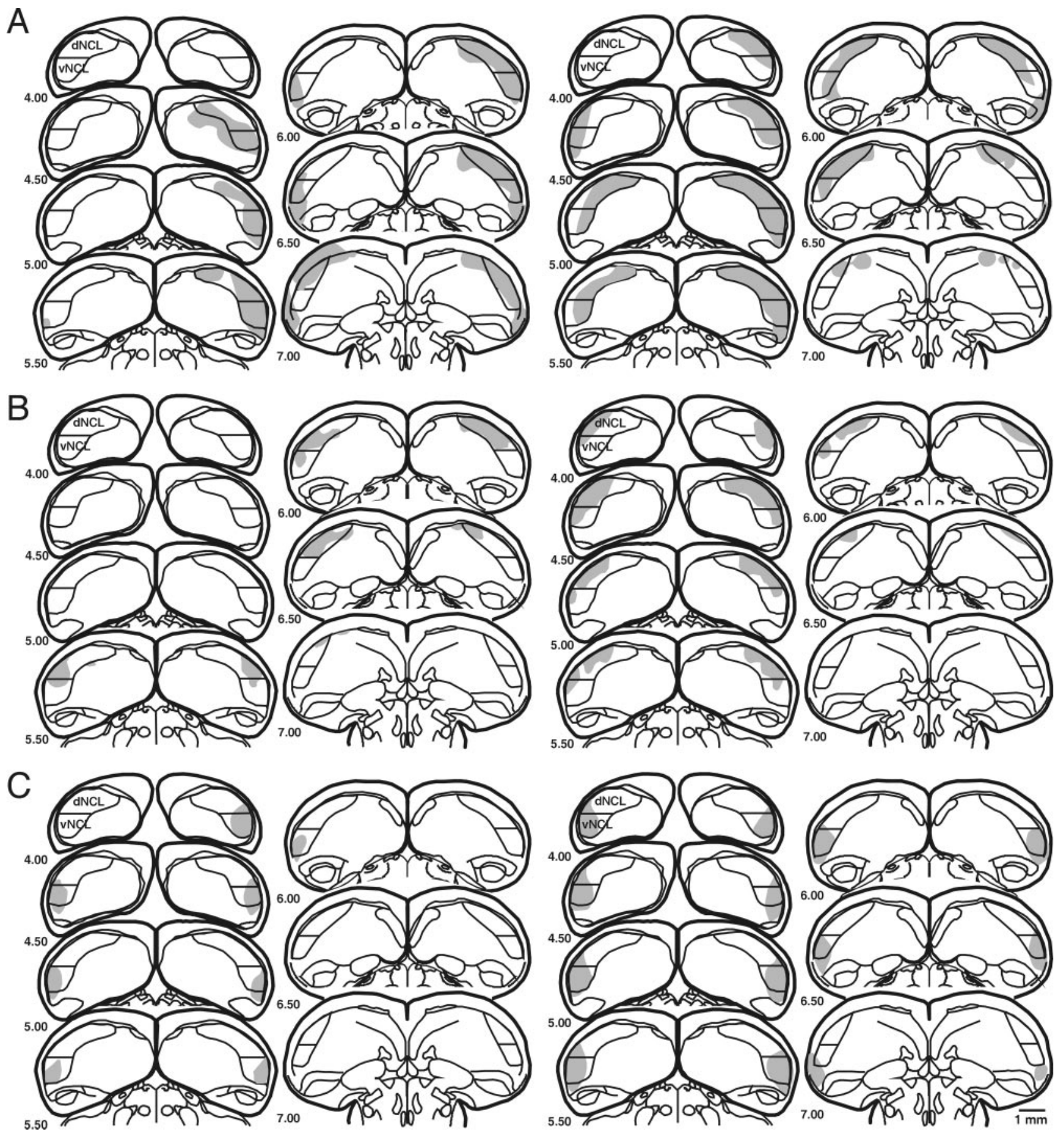

Figure 1. Reconstruction of the extent of NCL lesions in animals with total NCL lesions $(A)$, dorsal NCL lesions $(B)$, and ventral NCL lesions $(C)$. Schematic frontal sections (caudal to frontal A 4.00-7.00) are taken from the pigeon brain atlas of Karten and Hodos (1967). The outline of the NCL is defined by Waldmann and Güntürkün (1993) on the basis of the density of dopaminergic fibers, and the division into a dorsal and ventral NCL is based on neurochemical data by Riters et al. (1999). Lesions are depicted as shaded areas. Lesion reconstructions are shown for the smallest (left columns) and largest (right columns) case of each group.

their performance significantly from the first to the second postoperative test period (both $p$ values $<0.05$ ), whereas no changes were observed in the dorsal lesion group.

When the individual differences in preoperative performance were taken into account, the effects of different NCL lesions on the performance in the DMTS task were remarkably clear $\left(F_{(3,16)}=\right.$ 5.479; $p<0.009$ ) (Fig. 3A,B). Post hoc analyses showed that the performance of the dorsal lesion group was impaired severely compared with the control group $(p<0.05)$. There was no effect of the delay interval on the change in performance $\left(F_{(2,32)}=0.126\right.$; $p=0.882)$, because the decrease in performance was very similar for all delays (Fig. 3A). A significant effect of the test period on the change in performance $\left(F_{(1,16)}=6.951 ; p<0.018\right)$ and a significant interaction between the test period and lesion group $\left(F_{(3,16)}=\right.$ 3.851; $p<0.030$ ) were observed. With the exception of the control group, which showed no difference in performance, all lesion 

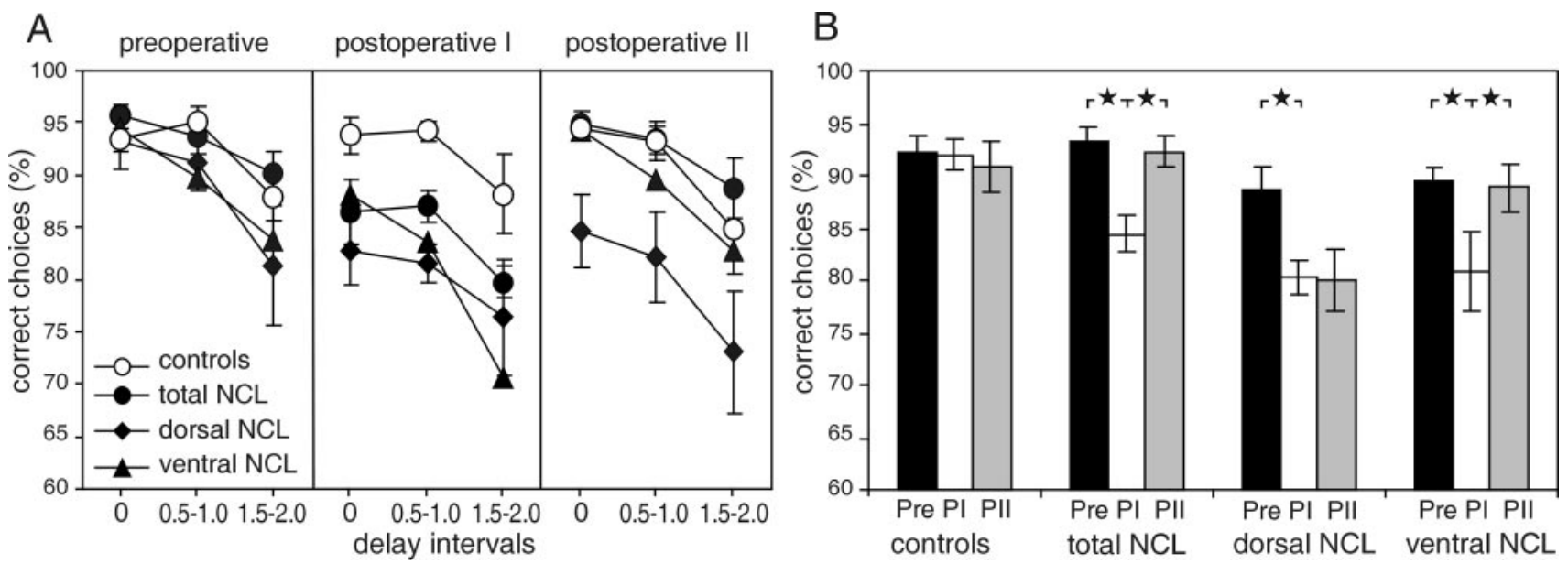

Figure 2. Performance ( $\pm \mathrm{SE})$ for the three lesion groups and controls during the DMTS task. $A$, Percentage correct choices for each of the three delay intervals during the preoperative testing and two postoperative test periods. $B$, Overall mean correct performance $( \pm \mathrm{SE})$ during the preoperative and postoperative test periods. The preoperative performance (Pre) is compared with the performance during the six sessions conducted within $10 \mathrm{~d}$ after surgery $(P I)$ and the six sessions conducted 3 weeks after surgery $(P I I) . \star p<0.05$.
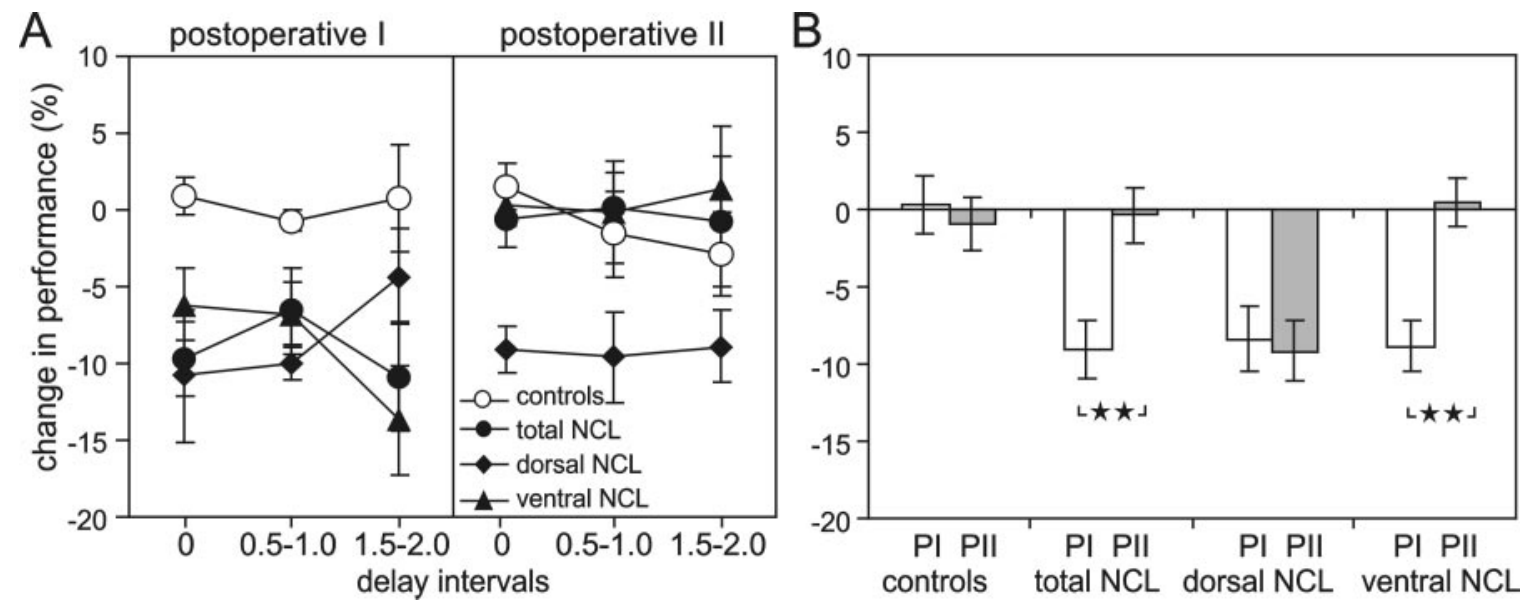

Figure 3. Change in performance $( \pm \mathrm{SE})$ after lesion surgery relative to preoperative performance levels (defined as $100 \%)$ for the three lesion groups and controls. $A$, Difference in the percentage correct choices for each of the three delay levels. Positive values indicate that more correct choices were made during postoperative than preoperative sessions. Negative values indicate a decrease in performance compared with preoperative sessions. $B$, Overall change in performance $( \pm \mathrm{SE})$ during the first $(P I)$ and second $(P I I)$ postoperative test periods for each treatment group. $\star \star p<0.01$.

groups showed a drop in performance from preoperative levels to postoperative levels by $\sim 8.5 \%$. After the rest period, the total and ventral lesion groups had improved their performance significantly $(p<0.01)$ (Fig. $3 A)$, so that pigeons of the total and ventral lesion groups performed the DMTS task during the second test period with almost the same accuracy as before surgery. Only the dorsal lesion group showed no tendency toward recovery and still accumulated on average $\sim 8.5 \%$ more errors during the second test period than before surgery.

Perseveration scores. Because deficits were delay independent, perseveration, the tendency to repeatedly activate the same response key or choose the same color, was analyzed across all delay intervals separately for spatial and color choices (Fig. 4A,B). Initially, spatial $(1.22 \pm 0.02)$ and color $(1.28 \pm 0.03)$ perseveration scores were approximately equal. An ANOVA on the spatial perseveration scores revealed a main effect of treatment group $\left(F_{(3,16)}=7.873 ; p=0.002\right)$ and test period $\left(F_{(2,32)}=9.293\right.$; $p<0.001)$ and a significant interaction between these factors $\left(F_{(6,32)}=2.703 ; p=0.031\right)$. Subsequent post hoc tests showed that spatial perseveration scores were significantly higher during the first postoperative test period than during the preoperative and the second postoperative test period $(p<0.05)$. In particular, animals of the dorsal and total lesion groups showed a significant increase in spatial perseveration behavior during the first test period after lesion surgery $(p<0.05)$. During the second postoperative test period, their spatial perseveration scores were not different from normal levels. The ventral and control groups showed no significant variation in their spatial perseveration behavior between preoperative and postoperative sessions.

Color perseveration scores were also affected strongly by the lesion treatment. Although there was no overall difference in color perseveration scores between different groups $\left(F_{(3,16)}=\right.$ $1.902 ; p=0.170)$, there was a significant increase in the tendency to perseverate when preoperative and postoperative sessions were compared $\left(F_{(2,32)}=7.062 ; p<0.003\right)$. As in the case of spatial perseveration scores, color perseveration scores were elevated significantly during the first postoperative test period compared with preoperative sessions and recovered during the second postoperative test period $(p<0.05)$. The ANOVA also showed a significant interaction between the lesion treatment and test pe- 
A

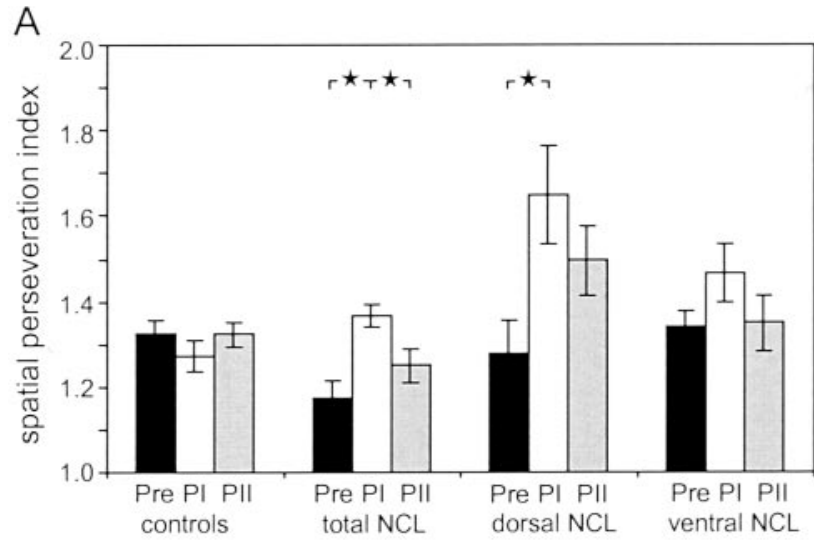

B

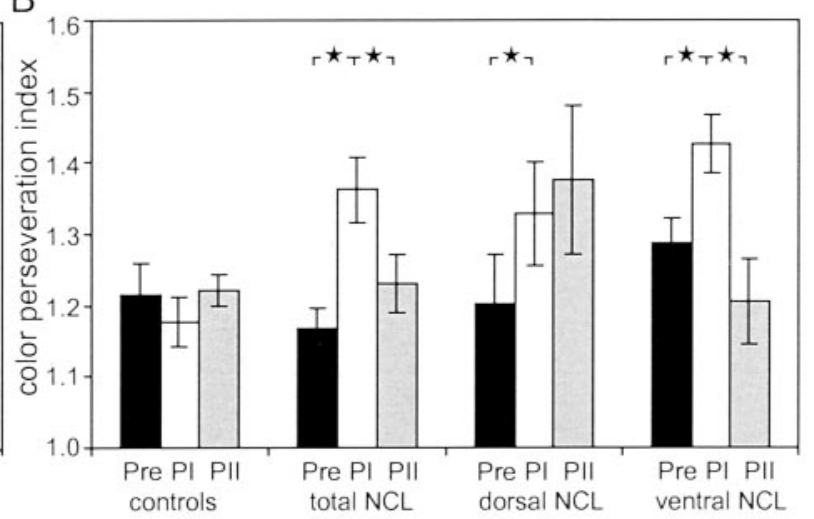

Figure 4. Perseveration scores $( \pm \mathrm{SE})$ for all groups during the preoperative and first $(P I)$ and second $(P I I)$ postoperative test periods. Scores higher than 1 indicate a tendency to perseverate choices. There was a tendency to perseverate choices with respect to the spatial position $(A)$ or with respect to color $(B) \star \star p<0.05$.

$\operatorname{riod}\left(F_{(6,32)}=4.275 ; p<0.003\right)$. Lesions of the ventral, dorsal, or total NCL resulted in a significant increase in color perseveration scores during the first postoperative test period, whereas sham operations caused no adverse effect. Animals with ventral or total NCL lesions recovered and had significantly lower color perseveration scores during the second than the first postoperative test period, whereas animals of the dorsal lesion group remained at the same high level of perseveration as before.

\section{Response times}

Birds of the different lesion groups did not show any differences in their response behavior in the DMTS task. Their response times, i.e., the time to activate the response key after stimulus presentation, were similar $\left(F_{(3,16)}=0.477 ; p=0.703\right)$ and did not change during the preoperative and two postoperative test periods $\left(F_{(2,32)}=1.900 ; p=0.166\right)$. No interactions between these factors were observed $\left(F_{(6,32)}=1.399 ; p=0.246\right)$.

\section{DISCUSSION}

\section{Role of the avian NCL in object-related working memory}

Results of the present study demonstrate that the pigeon's NCL is involved crucially in nonspatial, object-related working memory in which the color of the sample stimulus has to be maintained during a delay. Large as well as partial lesions of the ventral or dorsal NCL caused robust impairments in the DMTS task. Our conclusion that working memory in the NCL is not always linked to spatial processing is supported by the fact that all lesioned animals showed an increase in perseverative responses to color, indicating that their behavior was guided by the color of the choice stimuli. These data complement previous reports that demonstrated the participation of the NCL in spatial working memory (Mogensen and Divac, 1982, 1993; Güntürkün, 1997a).

Deficits in such delay tasks are very likely caused by impairments in working memory. As shown in the present and other studies, NCL lesions do not interfere with sensory or motor processes (Mogensen and Divac, 1982, 1993; Güntürkün, 1997a). In addition, the DMTS performance showed the typical decline in response accuracy with longer delays, indicating increased demands on short-term memory. Even in the 0 sec delay condition, animals had to memorize the sample, because it was never presented simultaneously with the choice stimuli. NCL lesions caused a delay-independent, parallel shift in performance with an increase of errors by $\sim 10 \%$. Thus, lesions did not add an additional, nonlinear component to the performance function, which would have indicated impairments of functions not related to working memory. Delay-independent effects are also observed after PFC inactivation or lesions in rats and monkeys (Shindy et al., 1994; Rushworth et al., 1997; Dunnett et al., 1999).

\section{Comparison with the mammalian PFC}

On the basis of the crucial role of the NCL in spatial working memory and its dense dopaminergic innervation, Mogensen and Divac (1982) were the first who compared the avian NCL with the mammalian PFC. Until the present study, behavioral data concerning the involvement of the NCL in nonspatial working memory were lacking. However, anatomic (Pandya and Yeterian, 1990; Fuster, 1997), behavioral (Levy and Goldman-Rakic, 2000; Postle et al., 2000), and electrophysiological (Fuster, 1997; Goldman-Rakic, 1999) studies demonstrate clearly that the PFC is a supramodal integration area able to store information of different modalities in working memory. Thus, if the NCL assumes functions similar to those of the PFC, it clearly should be of crucial importance in spatial (Mogensen and Divac, 1982, 1993; Güntürkün, 1997a; Hartmann and Güntürkün, 1998) as well as in nonspatial working memory processes, which is finally demonstrated in this study.

Connectional data also support the notion that the NCL is a supramodal processing area. Like the PFC, the NCL receives afferents from all sensory systems (Metzger et al., 1998; Kröner and Güntürkün, 1999). Projection areas of different modalities overlap extensively within the NCL (Kröner and Güntürkün, 1999). In addition, dendritic and axonal arbors of principal NCL neurons surpass modality-specific subareas and create a multimodal network (Kröner et al., 2002). Electrophysiological data also indicate that NCL and PFC are functionally comparable association areas. NCL neurons activated during delay periods of a go/no-go task may play a role in holding information by sustained levels of activity, similar to PFC neurons (Fuster, 1997; Kalt et al., 1999; Diekamp et al., 2002). The NCL is innervated massively by dopaminergic fibers, which is crucial for cognitive and executive functions (Waldmann and Güntürkün, 1993; Durstewitz et al., 1998). Prefrontal $D_{1}$ receptors play a major role in working memory in the mammalian PFC (Sawaguchi and Goldman-Rakic, 1994; Goldman-Rakic, 1999); likewise, local blockade of $\mathrm{D}_{1}$ receptors in NCL interfere with working memory (Diekamp et al., 
2000; Güntürkün and Durstewitz, 2001). However, despite the astounding number of similarities, histochemical, genetic, and anatomic studies indicate that the NCL and PFC are not homologous structures but instead represent a remarkable case of convergent evolution (Medina and Reiner, 2000; Puelles et al., 2000; Redies et al., 2001). Thus, the PFC and NCL may share common biochemical and network features that are of crucial importance for working memory and participation in higher cognitive processes.

\section{Functional subdivision of the NCL}

Impairments after dorsal but not ventral NCL lesions in nonspatial working memory and spatial learning (Riters and Bingman, 1999) provide evidence for functional subdivisions within the avian NCL. Paradoxically, complete recovery from temporary deficits occurs in animals with total NCL lesions (Mogensen and Divac, 1982, 1993), whereas smaller dorsal NCL lesions cause long-lasting DMTS impairments. Our correlation analysis shows that the functional recovery and magnitude of impairment were not a function of lesion size. In fact, large lesions sometimes induce similar (Grafman et al., 1988) or even fewer (Sprague 1966; Irle and Markowitsch, 1990; Wallace et al., 1990) behavioral deficits than small lesions. Recovery of functions after lesions is observed in many systems, including the PFC (Dunnett et al., 1999).

One explanation for the recovery in animals with total but not with dorsal NCL lesions might be that essential areas within the NCL or surrounding tissue were destroyed in dorsal lesions that were spared in total NCL lesions. However, a careful analysis of the precise location of lesions makes this very unlikely. Another possibility might be that birds with dorsal lesions received larger lesions in the left NCL than birds of the total lesion group and that asymmetric lesions cause long-lasting deficits because of a left-hemispheric dominance for object discrimination (Güntürkün, 1997b). This contradicts our analysis showing that both hemispheres contributed equally to DMTS performance. Another explanation assumes that partial sparing may interfere to a larger extent with the reorganization of neural systems than the complete loss of an area (Nau and Delius, 1981; Wallace et al., 1989; Irle, 1990). Accordingly, total rather than small dorsal NCL lesions would facilitate the reorganization or recruitment of forebrain circuits mediating working memory. An additional possibility for the different recovery effects is that ventral NCL mediates perseverative behavior or interferes with response inhibition, which are important aspects of executive functions and are affected by prefrontal lesions in mammals (Granon et al., 1994; Collins et al., 1998; Dunnett et al., 1999). In birds with dorsal NCL lesions, perseveration behavior mediated by the activity of the remaining ventral NCL might be accentuated, causing longterm deficits. In birds with ventral or total NCL lesions, which indeed showed only a small or nonsignificant increase in spatial perseveration, these negative effects are removed, and thus these animals are able to improve their DMTS performance over time.

These functional subdivisions are consistent with the biochemically defined dorsal and ventral partitions of the NCL on the basis of the distribution of tyrosine hydroxylase, choline acetyltransferase, and substance P (Riters et al., 1999). The dorsal NCL is characterized by a high density of tyrosine hydroxylase-positive fibers, relating to the importance of dopamine in working memory (Goldman-Rakic, 1999), and by substance P, which has favorable effects on cognitive functions (Bennett et al., 1997). The dorsal and ventral NCL also differ in their connectivity. Only the dorsal NCL receives afferents from multimodal thalamic nuclei (Korzeniewska and Güntürkün, 1990; Güntürkün and Kröner, 1999). The caudoventral NCL sends efferents predominantly to limbic structures of the striatum, whereas other areas of the NCL project to sensorimotor portions of the striatum (Kröner and Güntürkün, 1999). The connections linking the ventral and dorsal NCL with different areas of the ventral and dorsal striatum might be related to their specific functions in working memory and executive functions. In addition, the dorsal but not ventral NCL is connected with a complex of association structures, the mediorostral neostriatum/hyperstriatum $(\mathrm{MNH})$ and the intermediate and medial hyperstriatum ventrale (IMHV) (Metzger et al., 1998; Kröner and Güntürkün, 1999). Long-lasting deficits after dorsal NCL ablations might derive from lesioning of this crucial cognitive link of the avian forebrain. In chicks, the MNH/IMHV complex plays a pivotal role in filial imprinting (Maier and Scheich, 1983; Horn, 1985; Braun et al., 1999) and one-trial passive avoidance learning (Rose, 2000). In songbirds, the projection from the medial magnocellular nucleus of the anterior neostriatum to the high vocal center (Foster et al., 1997; Vates et al., 1997; Foster and Bottjer, 2001), which is involved in learning and memory aspects of song learning, is probably equivalent to that of the MNH to the NCL in pigeons and chicks. All of these studies suggest that the projection from the anteromedial forebrain to the dorsal NCL is an important axis of cognitive operations in different species of birds.

In conclusion, our findings provide additional evidence for the existence of functionally distinct regions within the avian NCL and support previous models of anatomically, neurochemically, and behaviorally defined subdivisions. In addition, the data show that the NCL plays a crucial role in object-related working memory and thus demonstrate its ability to maintain nonspatial as well as spatial information in working memory. Additional studies should give detailed insights about the role of these constituents of the NCL in working memory and cognitive functions. In comparison with investigations on the mammalian association cortex, data concerning the avian NCL might add notably to the understanding of mechanisms and different processing modules involved in working memory.

\section{REFERENCES}

Aldavert-Vera L, Costa-Miserachs D, Divac I, Delius JD (1999) Presumed "prefrontal cortex" lesions in pigeons: effects on visual discrimination performance. Behav Brain Res 102:165-170.

Bennett GW, Ballard TM, Watson CD, Fone KC (1997) Effect of neuropeptides on cognitive function. Exp Gerontol 32:451-469.

Bradley P, Davies DC, Horn G (1985) Connections of the hyperstriatum ventrale of the domestic chick (Gallus domesticus). J Anat 140:577-589.

Braun K, Bock J, Metzger M, Jiang S, Schnabel R (1999) The dorsocaudal neostriatum of the domestic chick: a structure serving higher associative functions. Behav Brain Res 98:211-218.

Collins P, Roberts AC, Dias R, Everitt BJ, Robbins TW (1998) Perseveration and strategy in a novel spatial self-ordered sequencing task for nonhuman primates: effects of excitotoxic lesions and dopamine depletions of the prefrontal cortex. J Cognit Neurosci 10:332-354.

Diekamp B, Kalt T, Ruhm A, Koch M, Güntürkün O (2000) Impairment in a discrimination reversal task after D1 receptor blockade in the pigeon "prefrontal cortex." Behav Neurosci 114:1145-1155.

Diekamp B, Kalt T, Güntürkün O (2002) Working memory neurons in pigeons. J Neurosci 22:RC210(1-5).

Divac I, Mogensen J (1985) The prefrontal "cortex" in the pigeon: catecholamine histofluorescence. Neuroscience 15:677-682.

Divac I, Mogensen J, Bjorklund A (1985) The prefrontal "cortex" in the pigeon: biochemical evidence. Brain Res 332:365-368.

Dunnett SB, Nathwani F, Brasted PJ (1999) Medial prefrontal and neostriatal lesions disrupt performance in an operant delayed alternation task in rats. Behav Brain Res 106:13-28.

Durstewitz D, Kröner S, Hemmings Jr HC, Güntürkün O (1998) The dopaminergic innervation of the pigeon telencephalon: distribution of 
DARPP-32 and co-occurrence with glutamate decarboxylase and tyrosine hydroxylase. Neuroscience 83:763-779.

Foster EF, Bottjer SW (2001) Lesions of a telencephalic nucleus in male zebra finches: influences on vocal behavior in juveniles and adults. J Neurobiol 46:142-165.

Foster EF, Mehta RP, Bottjer SW (1997) Axonal connections of the medial magnocellular nucleus of the anterior neostriatum in zebra finches. J Comp Neurol 382:364-381.

Fuster JM (1997) The prefrontal cortex. Philadelphia: Lippincott-Raven.

Gagliardo A, Bonadonna F, Divac I (1996) Behavioral effects of ablations of the presumed "prefrontal cortex" or the corticoid in pigeons. Behav Brain Res 78:155-162.

Gagliardo A, Mazzotto M, Divac I (1997) Memory of radial maze behavior in pigeons after ablations of the presumed equivalent of mammalian prefrontal cortex. Behav Neurosci 111:955-962.

Goldman-Rakic PS (1999) The "psychic" neuron of the cerebral cortex. Ann NY Acad Sci 868:13-26.

Grafman J, Jonas BS, Martin A, Salazar AM, Weingartner H, Ludlow C, Smutok MA, Vance SC (1988) Intellectual function following penetrating head injury in Vietnam veterans. Brain 111:169-184.

Granon S, Vidal C, Thinus-Blanc C, Changeux JP, Poucet B (1994) Working memory, response selection, and effortful processing in rats with medial prefrontal lesions. Behav Neurosci 108:883-891.

Güntürkün O (1997a) Cognitive impairments after lesions of the neostriatum caudolaterale and its thalamic afferents in pigeons: functional similarities to the mammalian prefrontal system? J Hirnforsch 38:133-143.

Güntürkün O (1997b) Avian visual lateralization: a review. NeuroReport 8:iii-xi.

Güntürkün O, Durstewitz D (2001) Multimodal areas of the avian forebrain: blueprints for cognition. In: Brain evolution cognition (Roth $\mathrm{G}$, Wulliman MF, eds), pp 431-450. New York: Wiley.

Güntürkün O, Kesch S (1987) Visual lateralization during feeding in pigeons. Behav Neurosci 101:433-435.

Güntürkün O, Kröner S (1999) A polysensory pathway to the forebrain of the pigeon: the ascending projections of the nucleus dorsolateralis posterior thalami (DLP). Eur J Morphol 37:185-189.

Hartmann B, Güntürkün O (1998) Selective deficits in reversal learning after neostriatum caudolaterale lesions in pigeons: possible behavioral equivalencies to the mammalian prefrontal system. Behav Brain Res 96:125-133.

Horn G (1985) Memory, imprinting and the brain. Oxford: Clarendon.

Irle E (1990) An analysis of the correlation of lesion size, localization and behavioral effects in 283 published studies of cortical and subcortical lesions in old-world monkeys. Brain Res Brain Res Rev 15:181-213.

Irle E, Markowitsch HJ (1990) Functional recovery after limbic lesions in monkeys. Brain Res Bull 25:79-92.

Kalt T, Diekamp B, Güntürkün O (1999) Single unit activity during a go/nogo task in the neostriatum caudolaterale in the pigeon: functional equivalencies to the prefrontal cortex. Brain Res 839:263-278.

Karten HJ, Hodos W (1967) A stereotaxic atlas of the brain of the pigeon (Columba livia). Baltimore: Johns Hopkins.

Korzeniewska E, Güntürkün O (1990) Sensory properties and afferents of the N. dorsolateralis posterior thalami of the pigeon. J Comp Neurol 292:457-479.

Kröner S, Güntürkün O (1999) Afferent and efferent connections of the caudolateral neostriatum in the pigeon (Columba livia): a retro- and anterograde pathway tracing study. J Comp Neurol 407:228-260.

Kröner S, Gottmann K, Hatt H, Güntürkün O (2002) Electrophysiological and morphological properties of cell types in the chick neostriatum caudolaterale. Neuroscience 110:459-473.

Leutgeb S, Husband S, Riters LV, Shimizu T, Bingman VP (1996) Telencephalic afferents to the caudolateral neostriatum of the pigeon. Brain Res 730:173-181.

Levy R, Goldman-Rakic PS (2000) Segregation of working memory functions within the dorsolateral prefrontal cortex. Exp Brain Res 133:23-32.

Maier V, Scheich H (1983) Acoustic imprinting leads to differential
2-deoxy-D-glucose uptake in the chick forebrain. Proc Natl Acad Sci USA 80:3860-3864.

Medina L, Reiner A (2000) Do birds possess homologues of mammalian primary visual, somatosensory and motor cortices? Trends Neurosci 23:1-12.

Metzger M, Jiang S, Braun K (1998) Organization of the dorsocaudal neostriatal complex: a retrograde and anterograde tracing study in the domestic chick with special emphasis on pathways relevant to imprinting. J Comp Neurol 395:380-404.

Mogensen J, Divac I (1982) The prefrontal "cortex" in the pigeon: behavioral evidence. Brain Behav Evol 21:60-66.

Mogensen J, Divac I (1993) Behavioural effects of ablation of the pigeon-equivalent of the mammalian prefrontal cortex. Behav Brain Res 55:101-107.

Nau F, Delius JD (1981) Discrepant effects of unilateral and bilateral forebrain lesions on the visual performance of pigeons. Behav Brain Res 2:119-124.

Pandya DN, Yeterian EH (1990) Prefrontal cortex in relation to other cortical areas in rhesus monkey: architecture and connections. Prog Brain Res 85:63-94.

Postle BR, Stern CE, Rosen BR, Corkin S (2000) An fMRI investigation of cortical contributions to spatial and nonspatial visual working memory. NeuroImage 11:409-423.

Puelles L, Kuwana E, Puelles E, Bulfone A, Shimamura K, Keleher J, Smiga S, Rubenstein JLR (2000) Pallial and subpallial derivatives in the embryonic chick and mouse telencephalon, traced by the expression of the genes dlx-2, Emx-1, Nkx-2.1, Pax-6, and Tbr-1. J Comp Neurol 424:409-438.

Redies C, Medina L, Puelles L (2001) Cadherin expression by embryonic divisions and derived gray matter structures in the telencephalon of the chicken. J Comp Neurol 438:253-285.

Rehkämper G, Zilles K (1991) Parallel evolution in mammalian and avian brains: comparative cytoarchitectonic and cytochemical analysis. Cell Tissue Res 263:3-28.

Riters LV, Bingman VP (1999) The effects of lesions to the caudolateral neostriatum on sun compass based spatial learning in homing pigeons. Behav Brain Res 98:1-15.

Riters LV, Erichsen JT, Krebs JR, Bingman VP (1999) Neurochemical evidence for at least two regional subdivisions within the homing pigeon (Columba livia) caudolateral neostriatum. J Comp Neurol 412:469-487.

Rose SP (2000) God's organism? The chick as a model system for memory studies. Learn Mem 7:1-17.

Rushworth MF, Nixon PD, Eacott MJ, Passingham RE (1997) Ventral prefrontal cortex is not essential for working memory. J Neurosci 17:4829-4838

Sawaguchi T, Goldman-Rakic PS (1994) The role of D1-dopamine receptor in working memory: local injections of dopamine antagonists into the prefrontal cortex of rhesus monkeys performing an oculomotor delayed-response task. J Neurophysiol 71:515-528.

Shindy WW, Posley KA, Fuster JM (1994) Reversible deficit in haptic delay tasks from cooling prefrontal cortex. Cereb Cortex 4:443-450.

Sprague JM (1966) Interaction of cortex and superior colliculus in mediation of visually guided behavior in the cat. Science 153:1544-1547.

Urcuioli PJ, DeMarse TB, Lionello KM (1999) Sample-duration effects on pigeons' delayed matching as a function of predictability of duration. J Exp Anal Behav 72:279-297.

Vates GE, Vicario DS, Nottebohm F (1997) Reafferent thalamo"cortical" loops in the song system of oscine songbirds. J Comp Neurol 380:275-290.

Waldmann C, Güntürkün O (1993) The dopaminergic innervation of the pigeon caudolateral forebrain: immunocytochemical evidence for a "prefrontal cortex" in birds? Brain Res 600:225-234.

Wallace SF, Rosenquist AC, Sprague JM (1989) Recovery from cortical blindness mediated by destruction of nontectotectal fibers in the commissure of the superior colliculus in the cat. J Comp Neurol 284:429450.

Wallace SF, Rosenquist AC, Sprague JM (1990) Ibotenic acid lesions of the lateral substantia nigra restore visual orientation behavior in the hemianopic cat. J Comp Neurol 296:222-252. 